\title{
Effect of particles shape on magnetohydrodynamics hybrid nanofluid flow and heat transfer in porous medium with slip condition
}

\author{
Dianchen $\mathrm{Lu}^{1}$, Umair Rashid ${ }^{2}$, Muhammad Suleman ${ }^{1}$, Jamshaid Rahman ${ }^{1}$, and Hasan \\ Shahzad $^{3}$ \\ ${ }^{1}$ Jiangsu University \\ ${ }^{2}$ University of Science and Technology of China \\ ${ }^{3}$ Beijing University of Technology
}

November 9, 2020

\begin{abstract}
The objective of the present article is to analyze the magnetohydrodynamic hybrid nanofluid flow and heat transfer in a porous medium with the nanoparticles shape effect. The effect of thermal conductivity variation, slip condition and heat generation is also considered. The Sphere (spherical) and Lamina (non-spherical) shapes of $\mathrm{Al} 2 \mathrm{O} 3$ and $\mathrm{Cu}$ nanoparticle are suspended in pure water to form hybrid nanofluid. The partial differential equations (PDEs) of motion are converted into ordinary differential equation (ODEs) by well-known similarity transformation. The resultant ordinary differential equation (ODEs) are solved analytically with the help of Homotopy analysis method (HAM). Furthermore, the coeffects of physical parameters on velocity profiles, temperature profiles and Nusselt number are also taken into consideration. It is found that the performance of the Lamina (non-spherical) shapes nanoparticles on temperature disturbance and heat transfer is better than Sphere (spherical) shape nanoparticles Keywords: Nanoparticle shape,Nanofluid, Magnetic field, Homotopy analysis method.
\end{abstract}

\section{Hosted file}

Manuscript.pdf available at https://authorea.com/users/374342/articles/491883-effect-ofparticles-shape-on-magnetohydrodynamics-hybrid-nanofluid-flow-and-heat-transfer-inporous-medium-with-slip-condition

\section{Hosted file}

Figures.pdf available at https://authorea.com/users/374342/articles/491883-effect-ofparticles-shape-on-magnetohydrodynamics-hybrid-nanofluid-flow-and-heat-transfer-inporous-medium-with-slip-condition

\section{Hosted file}

Tables.pdf available at https://authorea.com/users/374342/articles/491883-effect-ofparticles-shape-on-magnetohydrodynamics-hybrid-nanofluid-flow-and-heat-transfer-inporous-medium-with-slip-condition 